\title{
Thrombolysis in Patients Aged over 80 Years Is Equally Effective and Safe
}

\author{
Petra M. Pego, MD,* Ana Paiva Nunes, MD, + Patricia Ferreira, MD, + \\ Cristina Sousa, MD, $†$ and Alexandre Amaral-Silva, MD††
}

\begin{abstract}
Background: Despite stroke's high prevalence in the elderly, intravenous thrombolysis is licensed in Europe only for patients younger than 80 years old. We aimed to compare the functional outcomes and complication rates in patients older versus younger than 80 years old treated with intravenous thrombolysis. Methods: A retrospective observational study of patients who received intravenous thrombolysis in a stroke unit between January 1, 2009, and June 30, 2012, was conducted. Variables were compared between 2 subgroups ( $\leq 80$ and $>80$ years). Results: Overall, 512 patients underwent intravenous thrombolysis, of which $13.1 \%$ were over 80 years. The mean age was 65.4 years in the younger subgroup and 82.9 years in the older subgroup. Prior independence rates did not differ between the subgroups. Prevalence of atrial fibrillation and cardioembolic stroke was higher in the older subgroup $(P=.004$ and .026). Only 3\% of the elderly with atrial fibrillation were taking oral anticoagulants. Symptoms-to-needle time was lower in the older subgroup $(P=.048)$. Stroke severity was higher in patients over 80 years $(P=.026)$. There was significant improvement in the National Institutes of Health Stroke Scale score 7 days after intravenous thrombolysis $(P<.001)$ in both subgroups. The proportion of patients with 3 months' favorable outcome and independence, hemorrhagic transformation, and mortality rates were similar in both subgroups. Conclusions: Elderly patients' benefits and outcomes from intravenous thrombolysis treatment were identical to the younger subgroup without excess hemorrhagic transformation or mortality. These results favor the use of intravenous thrombolysis in patients over 80 years. Key Words: Stroke-elderlythrombolysis-over 80 years.

(c) 2016 National Stroke Association. Published by Elsevier Inc. All rights reserved.
\end{abstract}

\section{Introduction}

Stroke is a major cause of mortality and morbidity constituting the second most frequent cause of death and

From the *Medicina 3, Hospital Distrital de Santarém, Cartaxo, Portugal; †Unidade CerebroVascular, Hospital de São José, Lisboa, Portugal; and $\ddagger$ Unidade de Neurologia, Hospital Vila Franca de Xira, Vila Franca de Xira, Portugal.

Received December 28, 2015; revision received February 23, 2016; accepted March 3, 2016.

Address correspondence to Petra M. Pego, MD, Medicina 3, Hospital Distrital de Santarém, Urbanização do Vapor, Lote 8, Cartaxo 2070-240,

Portugal. E-mail: petrapego@gmail.com.

$1052-3057 / \$$ - see front matter

(C) 2016 National Stroke Association. Published by Elsevier Inc. All rights reserved.

http:/ / dx.doi.org/10.1016/j.jstrokecerebrovasdis.2016.03.007 the third main cause of disability-adjusted life-years worldwide. ${ }^{1}$

Age is the most important nonmodifiable risk factor for stroke. In fact stroke's incidence increases with age in both genders, with an incidence of $38 \%$ in adults over 75 years old. ${ }^{2-4}$

However, despite stroke's high prevalence in the elderly, intravenous alteplase (intravenous recombinant tissue plasminogen activator [IV-rtPA]), the only approved treatment for pharmacological revascularization in acute ischemic stroke, is licensed only in Europe for use in patients younger than 80 years old. ${ }^{5}$ This seems to be related with frequent under-representation or exclusion of patients over the age of 80 years from clinical trials leading to uncertainty about the risk-benefit profile in these patients. ${ }^{6}$ 
Data regarding IV-rtPA treatment in this age group are conflicting and result mainly from observational studies. Most studies seem to show worse outcome and increased mortality in patients aged over 80 years old with acute ischemic stroke treated with IV-rtPA when compared with younger counterparts. ${ }^{7-17}$ Nevertheless, patients from this age group still seem to benefit from this treatment and do not seem to have an increased risk of symptomatic intracranial hemorrhage after IV-rtPA, as dem-

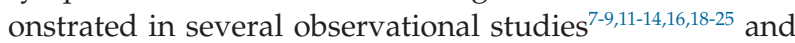
also in a randomized controlled trial. ${ }^{26}$ Thus, there is increasing evidence supporting the finding that old age, by itself, should not be a reason to exclude patients from treatment with IV-rtPA.

\section{Aims}

In the present study, we aimed to compare the functional outcomes and complication rates in patients older versus lower than 80 years old who were treated with IV-rtPA in our stroke unit. This study, which may be subjected to the bias inherent to the retrospective analysis, provides the benefit of the analysis on a real population, in a real setting, facing the need for clinical decisions in daily clinical practice.

\section{Methods}

We conducted a retrospective analysis of our prospective registry of patients who underwent IV-rtPA in our stroke unit between January 1, 2009, and June 30, 2012.

The patients were dichotomized in 2 subgroups: patients aged 80 years or younger and patients over 80 years old. Variables were compared between these subgroups.

Data were obtained from patient files and corporate database and were collected in Microsoft Office Excel 2010 (Microsoft Corporation, Redmond, WA).

Informed consent for IV-rtPA was obtained from patients aged over 80 years old or their relatives.

The information collected included demographic data (sex and age), stroke risk factors, time course data (date/ hour at the beginning of symptoms, arrival at the hospital, arrival at the computed tomography scan room, and beginning of IV-rtPA), vascular territory involved, subtype of ischemic stroke according to the Trial of Org 10172 in Acute Stroke Treatment (TOAST) classification, intracranial hemorrhage, and mortality. Severity was assessed by the National Institutes of Health Stroke Scale (NIHSS) (baseline, 2 and 24 hours, and 7 days after IV-rtPA). Functional outcomes at 90 days were measured according to modified Rankin Scale (mRS) and were assessed in a structured follow-up medical appointment 90 days after the stroke.

The primary outcomes that were defined for the present study were mortality rate; hemorrhagic transformation rate per Safe Implementation of Thrombolysis in StrokeMonitoring Study (SITS-MOST), per European Cooperative
Acute Stroke Study 2 (ECASS-2), and per National Institute of Neurological Disorders and Stroke (NINDS); and favorable outcome after 90 days, defined as an mRS score of $0-1$ in patients aged 80 years old or younger and in patients over 80 years old. Secondary outcomes were stroke severity (NIHSS score) 2 and 24 hours and 7 days after IV-rtPA and rate of independent outcome (mRS score $0-2$ ) and of severe disability/death (mRS score 5-6) 90 days after stroke in both age groups.

Statistical analysis was performed in SPSS Statistics 17.0 (SPSS Inc., Chicago, IL). Continuous variables are presented as means and standard deviations, and ordinal variables are presented as medians and interquartile ranges. Variables were compared between 2 two age subgroups using paired-samples $t$-test, independent-samples $t$-test, chi-square test, and Mann-Whitney $U$-test as indicated. A $P$ value less than .05 was considered representative of statistical significance.

\section{Results}

\section{Study Population}

A total of 512 patients underwent IV-rtPA in our unit between January 1, 2009, and June 30, 2012. All patients were included in the present study. Among these patients, $67(13.1 \%)$ were aged over 80 years.

\section{Baseline Characteristics}

The baseline characteristics of the patients in the present study are illustrated in Table 1.

The patients' age ranged between 22 and 92 years old. The mean age was $65.4 \pm 12.3$ years in the younger group and $82.9 \pm 2.4$ years in the older group $(P<.001)$. Majority of the patients $(56.8 \%)$ were male in the general population. In older patients, even though most patients were males, the percentage of female patients (46.3\%) was slightly higher than that in younger patients $(42.7 \%$, $P=.582)$.

The functional independence before stroke, defined by an mRS score of 1 or lower, did not differ significantly between age groups (95.1\% in younger patients, $92.5 \%$ in older patients; $P=.390$ ).

The risk factors for stroke differed between older and younger patients. Hypertension was the most prevalent risk factor in both groups and was more prevalent in older patients, but the difference was not statistically significant $(P=.066)$. Hyperlipidemia was the second more common risk factor in both groups. Atrial fibrillation was significantly more prevalent in patients over 80 years than in younger patients $(P=.004)$. Smoking was significantly more likely $(27.2 \%)$ in younger patients $(P=.007)$.

Patients over 80 years were previously medicated with acetylsalicylic acid significantly more often (37.3\%) than younger patients $(20.7 \%)(P=.002)$. In both age groups, most patients with atrial fibrillation were not medicated 
Table 1. Baseline characteristics

\begin{tabular}{|c|c|c|c|c|c|c|c|}
\hline & acteristics & Total & 80 years or younger & Over 80 years & $P$ & OR $(95 \% \mathrm{CI})$ & $\begin{array}{c}\text { Missing data, } \\
\mathrm{n}(\%)\end{array}$ \\
\hline \multicolumn{2}{|l|}{ Number $(\%)$} & 512 & $445(86.5)$ & $67(13.1)$ & & & \\
\hline \multicolumn{2}{|c|}{ Age (years), mean \pm SD (min-max) } & $67.7 \pm 13.0(22-92)$ & $65.4 \pm 12.3(22-80)$ & $82.9 \pm 2.4(81-92)$ & $<.001$ & & $0(0)$ \\
\hline \multicolumn{2}{|c|}{ Gender, female, n (\%) } & $221(43.2)$ & $190(42.7)$ & $31(46.3)$ & .582 & $.865(.517-1.449)$ & $0(0)$ \\
\hline \multicolumn{2}{|c|}{ Independence (mRS score $0-1$ ) before stroke number (\%) } & 485 (94.7) & $423(95.1)$ & $62(92.5)$ & .390 & $1.551(.566-4.244)$ & $0(0)$ \\
\hline \multirow[t]{11}{*}{ Risk factors } & Hypertension, $\mathrm{n}(\%)$ & $364(71.1)$ & $310(69.7)$ & $54(80.6)$ & .066 & $1.809(.955-3.425$ & $1(.2)$ \\
\hline & Diabetes mellitus, n (\%) & $129(25.2)$ & $117(26.3)$ & $12(17.9)$ & .141 & $.612(.316-1.182)$ & $0(0)$ \\
\hline & Hyperlipidemia, n (\%) & $261(51.0)$ & $230(51.7)$ & $31(46.3)$ & .418 & $.805(.481-1.347)$ & $3(.6)$ \\
\hline & Smoking, current, n (\%) & $81(15.8)$ & $78(17.5)$ & $3(4.5)$ & .022 & $.221(.068-.720)$ & $1(.2)$ \\
\hline & Smoking, previous, $\mathrm{n}(\%)$ & $48(9.4)$ & $43(9.7)$ & $5(7.5)$ & .565 & $.754(.288-1.977)$ & $1(.2)$ \\
\hline & Smoking, total n $(\%)$ & $129(25.2)$ & $121(27.2)$ & $8(11.9)$ & .007 & $.363(.169-.782)$ & $1(.2)$ \\
\hline & $\begin{array}{l}\text { Previous stroke in last } 3 \\
\text { months, } \mathrm{n}(\%)\end{array}$ & $15(2.9)$ & $11(2.5)$ & $4(6.0)$ & .113 & $2.505(.774-8.108)$ & $0(0)$ \\
\hline & $\begin{array}{l}\text { Previous stroke more than } \\
3 \text { months before, } \mathrm{n}(\%)\end{array}$ & $51(10)$ & $42(9.4)$ & $9(13.4)$ & .309 & $1.489(.689-3.218)$ & $0(0)$ \\
\hline & $\begin{array}{l}\text { Transient ischemic } \\
\text { accident, } \mathrm{n}(\%)\end{array}$ & $10(2)$ & $10(2.2)$ & $0(0)$ & .215 & $.867(.837-.897)$ & $0(0)$ \\
\hline & Atrial fibrillation, n (\%) & 143 (27.9) & $113(25.4)$ & $30(44.8)$ & .001 & $2.382(1.407-4.034)$ & $1(.2)$ \\
\hline & $\begin{array}{l}\text { Congestive heart failure, } \\
\mathrm{n}(\%)\end{array}$ & $107(20.9)$ & $87(19.6)$ & $20(29.9)$ & .053 & $1.751(.987-3.107)$ & $2(.4)$ \\
\hline \multirow[t]{3}{*}{ Medication } & $\begin{array}{l}\text { Acetylsalicylic acid } \\
\text { before stroke, n (\%) }\end{array}$ & $117(22.9)$ & $92(20.7)$ & $25(37.3)$ & .002 & $2.284(1.323-3.941)$ & $0(0)$ \\
\hline & Oral anticoagulants, $\mathrm{n}(\%)$ & $15(2.9)$ & $13(2.9)$ & $2(3.0)$ & .977 & $1.022(.226-4.635)$ & $0(0)$ \\
\hline & $\begin{array}{l}\text { Antihypertensive } \\
\text { medication, } \mathrm{n}(\%)\end{array}$ & $275(53.7)$ & $227(51)$ & 48 (71.6) & .002 & $2.426(1.382-4.259)$ & $0(0)$ \\
\hline \multirow[t]{3}{*}{ Time (min) } & Onset-to-door, mean $\pm \mathrm{SD}$ & $101.83 \pm 51.69$ & $104.06 \pm 52.26$ & $87.03 \pm 45.37$ & .012 & & $1(.2)$ \\
\hline & $\begin{array}{l}\text { Onset-to-treatment, } \\
\text { mean } \pm \text { SD }\end{array}$ & $153.16 \pm 79.28$ & $155.84 \pm 82.65$ & $135.18 \pm 47.84$ & .048 & & $3(.6)$ \\
\hline & $\begin{array}{l}\text { Door-to-treatment, } \\
\text { mean } \pm \text { SD }\end{array}$ & $51.32 \pm 67.50$ & $51.70 \pm 71.80$ & $48.76 \pm 23.28$ & .741 & & $3(.6)$ \\
\hline
\end{tabular}

Abbreviations: CI, confidence interval; mRS, modified Rankin Scale; OR, odds ratio; SD, standard deviation. Numerals in bold represent statistically significant associations $(P<0.05)$ 
with oral anticoagulants $(88.5 \%$ and $93.3 \%$ in the younger and older groups, respectively) and many hypertensive patients were not using antihypertensive medication (26.8\% and $11.1 \%$ in the younger and older groups, respectively).

Stroke onset-to-door and onset-to-treatment times were significantly shorter in patients over 80 years $(P=.012$ and .048 , respectively). There were no significant differences in door-to-treatment times between groups.

\section{Stroke-Related Characteristics}

Data regarding baseline stroke severity, vascular territory involved, and stroke subtype according to TOAST classification are shown in Table 2.

Baseline stroke severity was significantly higher $(P<.001)$ in patients over 80 years (median NIHSS score $15 \pm 12$ ) than in younger patients (median NIHSS score $10 \pm 10$ ).

Most strokes were located in anterior circulation in both age subgroups. Anterior circulation strokes were more frequent among older $(64.2 \%)$ than younger patients $(52.1 \%)$, but there were no statistically significant differences regarding location of stroke $(P=.216)$.

Globally, cardioembolic stroke was the most prevalent subtype, according to TOAST classification, and was more likely to occur in older patients, even though, globally, no statistically significant differences were found in stroke subtypes $(P=.301)$.

\section{Clinical Outcome and Hemorrhagic Transformation}

Table 3 and Figure 1 summarize data on clinical outcomes and hemorrhagic transformation.

Stroke severity was still significantly higher in older patients either 2 hours $(P=.023)$ or 7 days $(P=.025)$ after IV-rtPA (Table 3).

However, there were no significant differences in 3 months' outcome between the 2 age groups, with a similar proportion of patients in both groups reaching favorable outcome (Table 3).
There were also no significant differences in mortality $(P=.864)$ or hemorrhagic transformation rates $(P=.559$ per SITS-MOST, $P=.670$ per ECASS-2, and $P=.529$ per NINDS) between older and younger patients.

\section{Discussion}

Stroke in patients over 80 years has unique characteristics if compared with younger patients.

In our study, older patients' most prevalent risk factor was hypertension, similar to younger patients. Unlike other studies such as that of García-Caldentey et $\mathrm{al}^{14}{ }^{14}$ even though hypertension was more frequent in older than in younger patients, this difference did not achieve statistical significance. The prevalence of diabetes mellitus tended to be higher in younger than in older patients (not statistically significant), possibly partially due to an increase of the prevalence of diabetes in younger patients that may be related with changes in food habits and exercise. Older patients were, however, significantly more likely to have atrial fibrillation than younger patients, as described in previous studies. ${ }^{12,14,27}$ Moreover, cardioembolism as the main etiology was also observed in a higher proportion of older patients. Nevertheless, despite the finding that $44.8 \%$ of patients over 80 years had atrial fibrillation, only $3.0 \%$ of the patients were previously medicated with oral anticoagulants. This finding may be related with underdiagnosis of atrial fibrillation in some cases and possibly also with undermedication of previously diagnosed patients. Thus, one of the issues that the present study points out is the possible room for optimizing the primary prevention of stroke in older patients by ensuring active search for this arrhythmia and initiation of anticoagulation, providing there are no contraindications.

Also with reference to the vascular risk factors and previous medication, older patients were significant less likely to be current smokers, as described in previous studies, ${ }^{12,14,27}$ and were more likely to be

Table 2. Stroke-related characteristics

\begin{tabular}{|c|c|c|c|c|c|c|}
\hline \multicolumn{2}{|c|}{ Characteristics } & Total & $\begin{array}{c}80 \text { years or } \\
\text { younger }\end{array}$ & Over 80 years & $\begin{array}{c}\text { Missing data, } \\
\mathrm{n}(\%)\end{array}$ & $P$ \\
\hline \multicolumn{2}{|c|}{ NIHSS score on admission, median \pm IQR } & $11 \pm 10$ & $10 \pm 10$ & $15 \pm 12$ & 0 & $<.001$ \\
\hline \multirow[t]{3}{*}{ Location, n (\%) } & Anterior & $275(53.7)$ & $232(52.1)$ & $43(64.2)$ & $196(38.3)$ & .216 \\
\hline & Posterior & $26(5.1)$ & $23(5.2)$ & $3(4.5)$ & & \\
\hline & Anteroposterior & $5(1)$ & $5(1.1)$ & 0 & & \\
\hline \multirow{5}{*}{ TOAST classification, $\mathrm{n}(\%)$} & Large-artery atherosclerosis & $50(9.8)$ & $43(9.7)$ & $7(10.4)$ & $133(35)$ & .301 \\
\hline & Small-vessel occlusion & $78(15.2)$ & $68(15.3)$ & $10(14.9)$ & & \\
\hline & Cardioembolism & $134(26.2)$ & $109(24.5)$ & $25(37.3)$ & & \\
\hline & Undetermined etiology & 95 (18.6) & $84(18.9)$ & $11(16.4)$ & & \\
\hline & Other determined etiology & $22(4.3)$ & $22(4.9)$ & 0 & & \\
\hline
\end{tabular}

Abbreviations: IQR, interquartile range; NIHSS, National Institutes of Health Stroke Scale; TOAST, Trial of Org 10172 in Acute Stroke Treatment. Numerals in bold represent statistically significant associations $(P<0.05)$ 


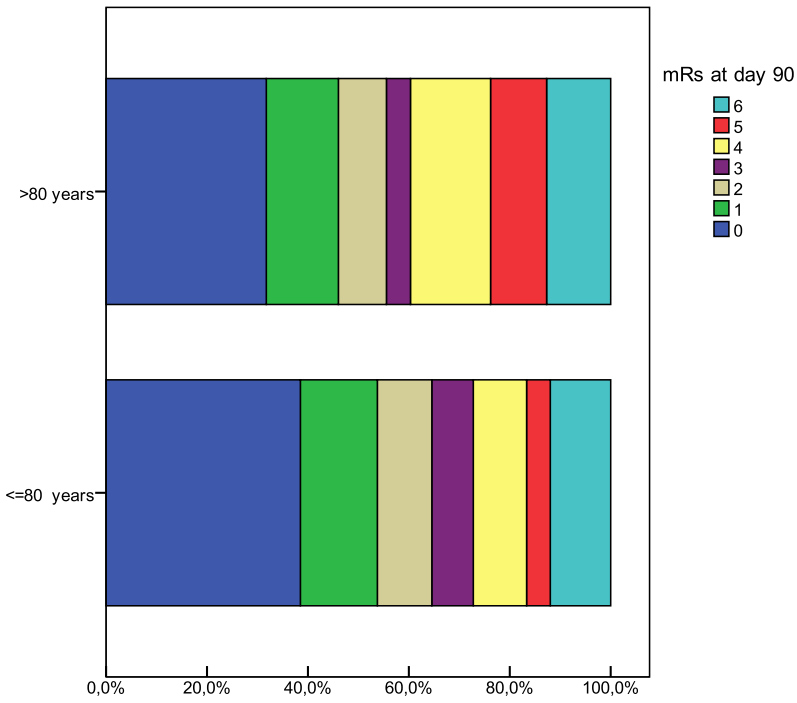

Figure 1. Three-month $m R S$ outcomes in patients 80 years or younger and in patients over 80 years old. Abbreviation: mRS, modified Rankin Scale.

medicated with acetylsalicylic acid and antihypertensive medication. This finding is presumably associated with a greater number of comorbidities as age increases. Also, many patients with hypertension were not medicated with antihypertensive therapy.

We also point out that there was no significant difference in previous functional status (mRS score) between older and younger patients, emphasizing that although many patients over 80 years were treated with IV-rtPA, their previous functional status was good. This is in contrast with some of the previous studies. ${ }^{12,16}$ In a recent study by Ford et al, ${ }_{1}^{16}$ previous independence before stroke was significantly less frequent in older than in younger patients. In Ford et al's study, IV-rtPA in older patients was associated with increased mortality and poorer outcome.

There was a significant difference in onset-to-door and onset-to-treatment times between age groups, which were significantly shorter in older patients. That was possibly explained by a more careful selection of patients over 80 years old who were adequate candidates to IV-rtPA, given that shorter time to treatment increases benefit and decreases risk, ${ }^{28}$ and taking into account the more dubious safety/benefit profile of these patients. Another possible contributing explanation may be the geographical context of the hospital with an elderly population living near the hospital, consequently having a quicker access.

The safety/benefit profile of IV-rtPA in older patients has been the subject of controversy for the past years. ${ }^{29}$ The results of our study show that, as previously reported, ${ }^{9,10,16}$ older patients tend to experience strokes with higher severity than younger patients (median NIHSS score of 15 versus 10). Despite these results, older patients still benefited from IV-rtPA. In fact, there were no 
significant differences in favorable outcome or independent outcome at day 90 between younger and older patients. Most previous studies had shown lower rates of favorable and independent outcomes at day 90 in patient aged over 80 years old.,12,15,16 However, a recent randomized controlled trial including 1617 patients over 80 years suggested that benefit does not seem to be diminished in the elderly. ${ }^{26}$ Also, in a study by Zeevi et al, ${ }^{19}$ older patients treated with IV-rtPA presented with a 12month modified Barthel Index score comparable to that of younger patients. Moreover, several studies revealed a similar rate of early neurological improvement in younger and older patients, ${ }^{7,9}$ and higher rates of early neurological improvement ${ }^{21}$ and improved functional outcome among elderly patients who underwent thrombolysis versus elderly patients who did not undergo thrombolysis. ${ }^{8,25}$

In the present study, hemorrhagic transformation or mortality rates at day 90 were similar in older and younger patients. Many other studies had previously reported similar rates of symptomatic and asymptomatic intracranial hemorrhages between younger and older patients. $7,9,11,14-16,19,20,23,24$ In contrast to our study, most previous studies revealed an increased 30-day

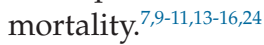

So, according to our results, older patients seem to also be likely to benefit in the short and long term from IVrtPA and do not seem to be in increased risk of mortality or hemorrhagic transformation.

Age by itself should not be a reason for exclusion of patients over 80 years from treatment with IV-rtPA. The positive results obtained must, however, be interpreted in light of a careful selection of patients as illustrated by the patients' favorable previous functional status or onsetto-treatment time. The necessity of adequate monitoring and level of care, evidence-based protocols, personnel training, and experience must also be noted to improve outcomes.

Our study has 2 main limitations. First, being a retrospective analysis of a prospective registry, we cannot exclude selection bias, including referral bias, of older patients, mostly because healthy elderly are possibly more likely to be referred and transferred for IV-rtPA. Second, the small sample size prevents the present study to detect small differences in infrequent outcomes.

\section{References}

1. Feigin VL, Forouzanfar MH, Krishnamurthi R, et al. Global Burden of Diseases, Injuries, and Risk Factors Study 2010 (GBD 2010) and the GBD Stroke Experts Group: global and regional burden of stroke during 1990-2010: findings from the Global Burden of Disease Study 2010. Lancet 2014;383:245-254.

2. Goldstein LB, Adams R, Alberts MJ, et al. Primary prevention of ischemic stroke: a guideline from the American Heart Association/American Stroke Association Stroke Council: cosponsored by the Atherosclerotic Peripheral Vascular Disease Interdisciplinary Working
Group; Cardiovascular Nursing Council; Clinical Cardiology Council; Nutrition, Physical Activity, and Metabolism Council; and the Quality of Care and Outcomes Research Interdisciplinary Working Group. Stroke 2006;37:1583-1633.

3. Chen RL, Balami JS, Esiri MM, et al. Ischemic stroke in the elderly: an overview of evidence. Nat Rev Neurol 2010;6:256-265.

4. Forti P, Maioli F, Procaccianti G, et al. Independent predictors of ischemic stroke in the elderly: prospective data from a stroke unit. Neurology 2013;80:29-38.

5. European Medicines Agency. Summary information on a referral opinion following an arbitration pursuant to Article 29 of Directive 2001/83/EC, for Actilyse International Non-Proprietary Name (INN): alteplase. Available at: http://www.ema.europa.eu/ema/index .jsp?curl=documents / document_library/Referrals _document/Actilyse_29/WC500010327.sjsp. 2002. Accessed October 12, 2014.

6. Wardlaw JM, Murray V, Berge E, et al. Thrombolysis for acute ischaemic stroke. Cochrane Database Syst Rev 2014;(7):CD000213.

7. Boulouis G, Dumont F, Cordonnier C, et al. Intravenous thrombolysis for acute cerebral ischaemia in old stroke patients $\geq 80$ years of age. J Neurol 2012;259:1461-1467.

8. Mishra NK, Ahmed N, Andersen G, et al. Thrombolysis in very elderly people: controlled comparison of SITS International Stroke Thrombolysis Registry and Virtual International Stroke Trials Archive. BMJ 2010;341:c6046.

9. Chen CI, Iguchi Y, Grotta JC, et al. Intravenous TPA for very old stroke patients. Eur Neurol 2005;54:140-144.

10. Mouradian M, Senthilselvan A, Jickling G, et al. Intravenous rt-PA for acute stroke: comparing its effectiveness in younger and older patients. J Neurol Neurosurg Psychiatry 2005;76:1234-1237.

11. Toni D, Lorenzano S, Agnelli G, et al. Intravenous thrombolysis with rt-PA in acute ischemic stroke patients aged older than 80 years in Italy. Cerebrovasc Dis 2008;25:129-135.

12. Sylaja PN, Cote R, Buchan AM, et al. Canadian Alteplase for Stroke Effectiveness Study (CASES) Investigators: thrombolysis in patients older than 80 years with acute ischaemic stroke: Canadian Alteplase for Stroke Effectiveness Study. J Neurol Neurosurg Psychiatry 2006;77:826-829.

13. Bray BD, Campbell J, Hoffman A, et al. Stroke thrombolysis in England: an age stratified analysis of practice and outcome. Age Ageing 2013;42:240-245.

14. García-Caldentey J, Alonso de Leciñana M, Simal P, et al. Intravenous thrombolytic treatment in the oldest old. Stroke Res Treat 2012;2012:923676.

15. Berrouschot J, Röther J, Glahn J, et al. Outcome and severe hemorrhagic complications of intravenous thrombolysis with tissue plasminogen activator in very old $(>$ or $=$ 80 years) stroke patients. Stroke 2005;36:2421-2425.

16. Ford GA, Ahmed N, Azevedo E, et al. Intravenous alteplase for stroke in those older than 80 years old. Stroke 2010;41:2568-2574.

17. Willey JZ, Ortega-Gutierrez S, Petersen N, et al. Impact of acute ischemic stroke treatment in patients $>80$ years of age: the specialized program of translational research in acute stroke (SPOTRIAS) consortium experience. Stroke 2012;43:2369-2375.

18. Zacharatos H, Hassan AE, Vazquez G, et al. Comparison of acute nonthrombolytic and thrombolytic treatments in ischemic stroke patients 80 years or older. Am J Emerg Med 2012;30:158-164. 
19. Zeevi N, Chhabra J, Silverman IE, et al. Acute stroke management in the elderly. Cerebrovasc Dis 2007;23:304308.

20. Pundik S, McWilliams-Dunnigan L, Blackham KL, et al. Older age does not increase risk of hemorrhagic complications after intravenous and/or intra-arterial thrombolysis for acute stroke. J Stroke Cerebrovasc Dis 2008; 17:266-272.

21. Ong CT, Sung SF, Wu CS, et al. Early neurological improvement after intravenous tissue plasminogen activator infusion in patients with ischemic stroke aged 80 years or older. J Chin Med Assoc 2014;77:179-183.

22. Sung PS, Chen $\mathrm{CH}$, Hsieh $\mathrm{HC}$, et al. Outcome of acute ischemic stroke in very elderly patients: is intravenous thrombolysis beneficial? Eur Neurol 2011;66:110-116.

23. Costello CA, Campbell BC, Perez de la Ossa N, et al. Age over 80 years is not associated with increased hemorrhagic transformation after stroke thrombolysis. J Clin Neurosci 2012;19:360-363.

24. Tanne D, Gorman MJ, Bates VE, et al. Intravenous tissue plasminogen activator for acute ischemic stroke in patients aged 80 years and older: the tPA stroke survey experience. Stroke 2000;31:370-375.
25. Mishra NK, Diener HC, Lyden PD, et al. Influence of age on outcome from thrombolysis in acute stroke: a controlled comparison in patients from the Virtual International Stroke Trials Archive (VISTA). Stroke 2010;41:2840-2848.

26. IST-3 Collaborative Group, Sandercock P, Wardlaw JM, et al. The benefits and harms of intravenous thrombolysis with recombinant tissue plasminogen activator within $6 \mathrm{~h}$ of acute ischaemic stroke (the third international stroke trial [IST-3]): a randomized controlled trial. Lancet 2012;379:2352-2363.

27. Rojas JI, Zurrú MC, Romano M, et al. Acute ischemic stroke and transient ischemic attack in the very old-risk factor profile and stroke subtype between patients older than 80 years and patients aged less than 80 years. Eur J Neurol 2007;14:895-899.

28. Lees KR, Bluhmki E, von Kummer R, et al. Time to treatment with intravenous alteplase and outcome in stroke: an updated pooled analysis of ECASS, ATLANTIS, NINDS, and EPITHET trials. Lancet 2010;375: 1695-1703.

29. Yayan J. Effectiveness of alteplase in the very elderly after acute ischemic stroke. Clin Interv Aging 2013;8:963-974. 